\title{
Neuromuscular, cognitive and metabolic implications of McArdle Syndrome: a global overview
}

\author{
Lucas Lima Vieira ${ }^{1}$, Rafaela de Lima Gomes Soares ${ }^{1}$, Stela Mirla da Silva Felipe ${ }^{1}$; Felipe Carmo de Moura ${ }^{1}$, Christina \\ Pacheco $^{1}$, Vânia Marilande Ceccatto ${ }^{1}$, Paula Matias Soares ${ }^{1,2}$, Gerly Anne de Castro Brito ${ }^{2}$ \\ ${ }^{I}$ Estate University of Ceara - Superior Institute of Biomedical Sciences; 1700, Dr. Silas Munguba Avenue, \\ Itaperi Campus, Fortaleza-CE, Brazil \\ ${ }^{2}$ Federal University of Ceara - Faculty of Medicine - Morphology Department, Delmiro de Farias Street, \\ Porangabuçu, Fortaleza-CE, Brazil \\ *Corresponding author e-mail:paula.soares@uece.br
}

Copyright () 2015 Lucas Lima Vieira et al. This is an open access article distributed under the Creative Commons Attribution License, which permits unrestricted use, distribution, and reproduction in any medium, provided the original work is properly cited.

\begin{abstract}
Carbohydrates are the main source of body energy and they can be stored in the organism in form of glycogen and degraded when there is a need for energy. However, McArdle Syndrome patients exhibit problems to degrade glycogen due to a deficiency in myophosphorylase enzyme, making these patients intolerant to high intensity exercises because a lack of ATP available in muscle cells. It has been found muscular weakness and subsarcolemmal accumulation of glycogen in muscle fibers and in neuronal cells in McArdle Syndrome patients. In its later-onset form, it is associated to muscular dysmorphia, myoglobinuria and rhabdomyolisis. Analyzing the biochemical aspects, it is possible to notice that these patients have a low rate of ATP production due to a reduction in the availability of glucose, reducing oxidative phosphorylation. However, the metabolic "second wind" effect allows the use of other energy sources. Excessively decreased exercise-induced lactate is also characteristic of patients with McArdle Syndrome. Electromyography studies describe alterations in nerve conduction and the necessity of recruiting more motor units to contract muscle in these patients. McArdle Syndrome produces several metabolic changes in patients due to absence of myophophorylase activity. The practice of aerobic exercise acts positively in these patients probably by increasing mitochondrial metabolism.
\end{abstract}

Keywords: Biochemistry; McArdle Syndrome; Metabolism; Mitochondrial Metabolism; Myophosphorylase.

\section{Introduction}

Several types of glycogen storage diseases (GSD) have been reported [1], [2], [3], varying from type 0 to type XIV. Those diseases, also known as glycogenoses, induce excessive accumulation of glycogen in the body, mainly due to deficiency of enzymes related to carbohydrates metabolism [3], whose structure may be normal or abnormal.

The GSD may be classified as a function of the defect enzyme involved, the patients' age, and the organs that are affected [4]. The subdivision of the GSD, in turn, is based on the particular type of carbohydrate metabolism-related enzyme deficiency. On these grounds, 14 distinct diseases have currently been identified:

- $\quad$ Type I, or Von Gierke's disease, which develops due to glucose-6-phosphatase deficiency [5];

- Type II, or Pompe's disease, which develops due to acid alpha glucosidase deficiency; it exhibits two different forms: early-onset (or the infantile form) and late-onset (or the juvenile/adult form) [6];

- Type III, or Cori's disease, which develops due to alteration of a glycogen debranching enzyme (4-alpha glucanotransferase); it is subdivided into subtypes IIIa, IIIb, IIIc and IIId as a function of the degree of enzyme deficiency [7];

- $\quad$ Type IV, or Andersen disease, which develops due to alteration of the glycogen branching enzyme [8];

- $\quad$ Type V, or McArdle Syndrome (MS), which develops due to myophosphorylase deficiency [9]; 
- $\quad$ Type VI, or Hers' disease, which develops due to liver phosphorylase deficiency [10]. Type VII results from phosphofructokinase deficiency [11], and types VIII and X were included in the latter category;

- $\quad$ Type IX, which develops due to deficiency of the liver phosphorylase kinase isoform PHK2 [12];

- Type XI, or Fanconi-Bickel Syndrome, which is caused by accumulation of the gene that encodes glucose transporter GLUT 2 [13];

- $\quad$ Type XII, or distal glycogenosis, which results from aldolase A deficiency [14];

- $\quad$ Type XIII, which develops due to $\beta$-enolase deficiency [15];

- $\quad$ Type XIV, which develops due to phosphoglucomutase deficiency [16]; and

- $\quad$ Type 0 , which develops due to glycogen synthase deficiency [17].

Although MS is caused by the deficiency of a muscle enzyme (myophosphorylase), it affects several organ systems, such as the nervous, cognitive and metabolic ones. These widespread effects occur because this enzyme participates in the breakdown of muscle glycogen, which serves as a source of energy for different cells, thus compromising muscle glycogenolysis [18].

An inability to breakdown muscle glycogen may result in the excessive storage of this polysaccharide, which can have several consequences. Individuals with GSD type V (GSD-V) usually exhibit muscle cramps, pain and fatigue during exercise and while performing the activities of daily life. Those symptoms may be due to a lack of ATP generation and regeneration by the anaerobic lactic system because the phosphorylase enzyme is unable to mobilize glycogen for hydrolysis. Consequently, the muscle fibers are exposed to acute ATP deficiency, with dysfunction of the membrane ion pumps, leading to an accelerated loss of membrane excitability, and then fatigue, cramps and downregulation of membrane ATPase [19]. There is controversy in the literature regarding the treatment of individuals with MS [20], [21]. Nevertheless, some authors have observed that exercise might contribute to reducing the symptoms of disease during its practice [22]. Although the fact that individuals with MS should avoid strenuous exercise is well established in the literature, a complete lack of exercise may result in a reduction of the muscle mitochondria content. This reduction could create further problems, as the mitochondrial enzymes play a crucial role in the metabolism of lipids [23], which constitute an energy source that is not directly affected in MS. In addition, the recommendation to refrain from exercise may further reduce the patients' exercise tolerance [24].

Thus, the aim of the present study was to perform a literature review of MS and its implications for the musculoskeletal and related systems and the therapeutic methods related to the practice of exercise.

\section{Methods}

The present study consisted of a literature survey on the subject of interest, for which purpose the following related keywords were used in all possible combinations: glycogenosis, McArdle Syndrome, action potential, musculoskeletal system, metabolism, and physical activity. The present article describes data gathered from books, periodical publications (mainly), essays, and masters' and doctoral dissertations. The SciELO, LILACS, PubMed, ScienceDirect, and BIREME databases were searched with no time limits to collect as much information as possible on the subject of interest.

\section{McArdle Syndrome}

MS was first described by Brian McArdle in an individual unable to increase venous lactate levels and breakdown glycogen while performing ischemic exercise [25]. MS is a rare disease that is caused by changes in the gene PYGM, which encodes the enzyme phosphorylase. Several PYGM gene mutations are associated with myophosphorylase defects, which points to the wide molecular heterogeneity of myophosphorylase deficiency and the absence of genotype-phenotype correlations [26], [27]. Mutations in the PYGM gene cause phosphorylase deficiency or its full absence during the course of glycogen metabolism, which impairs the generation of ATP from the breakdown of glycogen [28]. In their study, Zange et al. [29] found a reduction of the oxidative phosphorylation rate in 19 individuals with MS. A reduction or absence of glycogen breakdown in the first minutes of exercise training may be one of the main factors associated with the development of fatigue, muscle contracture and cramps, which are usually reported by individuals with MS [30].

Although most MS symptoms usually appear in childhood [30], diagnosis is often established only much later, in adulthood [20]. The disease manifestations vary from muscle fatigue, cramps, contracture and intolerance to exercise [24], [20] to more severe conditions, such as myoglobinuria (the presence of myoglobin in the urine, making it darker) and rhabdomyolysis (the breakdown of muscle tissue that leads to the release of muscle fiber contents into blood [31]. The action potential is also affected in patients with MS. Lorenzoni et al. [32] reported one case of MS in which needle electromyography showed a reduction of the compound muscle action potential amplitude following a short period of voluntary muscle activity or high-frequency repetitive stimulation. Those findings may have been observed due to absence of glycogen, which normally serves as an energy substrate for the active transport of ions through the neuronal membrane. 
Another striking feature of MS is the fact that, as a function of the reduction of the glycogen oxidation rate with a consequent decrease in the ATP levels, increase of ADP ones [19], which is attended by an exaggerated ammonia response and an increase in the serum creatine kinase level, with the latter being used as a disease marker [30]. The more severe symptoms are related to tubular necrosis that results from rhabdomyolisis [33].

Due to all of the above mentioned symptoms, the patient's often exhibit difficulty when performing simple activities of daily life, such as climbing stairs and moving objects.

Although the primary affected site in MS patients is the skeletal muscle, as a function of the isoenzyme deficiency that characterizes the disease, several authors have reported the association of other conditions. Moustafa, Patton, and Connelly [34] described a case of MS associated with obstructive hypertrophic cardiomyopathy in a patient without a family history of the latter. Nicholls et al. [35] reported the case of a patient with MS who developed angina. As a function of the MS rarity, it is still difficult to infer sound conclusions on the relationship between MS and cardiovascular disorders. Although the available data are not sufficient to assert such a relationship, the cardiovascular response to physical activity is known to be greater in individuals with MS compared to healthy ones [36].

Further, there is a single report in the literature of a case of MS associated with non-muscular complications affecting the respiratory system [37]. As in the case of the cardiovascular disorders, there is no conclusive evidence regarding the association of MS with respiratory disorders, which, in fact, may not be a consequence of the former.

\section{Implications of MS for the musculoskeletal system}

\subsection{Implications for the muscles}

As noted above, symptoms such as fatigue, muscle cramps and contracture have been described by individuals with MS who are subjected to exercise or other types of physical exertion [24], [20]. Although these symptoms usually appear in childhood, their onset may also occur later in life. In the latter case, the classic symptoms of disease appear in adulthood or old age. Felice, Schneebaum, and Jones [38] reported a case involving a physically active individual in whom the symptoms of disease - muscle cramps, upper limb weakness, and an increase in serum creatine kinase levels - appeared starting at 60 years old.

Additionally, Wolfe et al. [39] reported a case of late-onset of symptoms. The patient was 73 years old, physically active and had no history of intolerance to exercise until weakness appeared first in the left arm and, seven years later, also in the right arm, this patient additionally exhibited muscle atrophy.

Other patterns of permanent muscle weakness have also been described in individuals with MS. Some examples of such patterns are the "Limb Girdle", asymmetrical weakness mimicking facioscapulohumeral dystrophy (FSHD), and periscapular muscle weakness [40]. A systematic analysis showed that progressive muscle weakness and muscle dysmorphia occur more frequently among individuals with late-onset of MS symptoms [39]. However, the mechanism underlying the development of the late-onset symptoms has not yet been elucidated.

When clinical complaints are indicative of disease presence, diagnostic testing must be performed. One of the methods used to investigate the presence of MS is histochemical analysis of the muscle tissue, which may detect the subsarcolemmal accumulation of glycogen [20], [32], as was found in several cases. Such an accumulation may be due to excess glycogen that cannot be broken down. In one rare instance, Rubio et al. [41] found that in addition to the subsarcolemmal accumulation of glycogen, the patient also exhibited subsarcolemmal oxidative accumulation of the succinate dehydrogenase enzyme due to association of MS and NADH-ubiquinone reductase dysfunction, which was possibly caused by the patient's severe condition.

Glycogen accumulates not only at the muscle subsarcolemmal level, but also in other cells, such as axons and Schwann cells [42]. MS was also found to be associated with inclusion body myositis (IBM) [43] and myoadenylate deaminase deficiency [44].

Exercise tests are also used to improve the accuracy of diagnosis. Such tests might be based on biochemical analysis, such as the (ischemic or non-ischemic) forearm test, or on physiological responses, as observed in stress testing [36].

The forearm test is based on the fact that, as a function of deficient glycogenolysis, the blood lactate levels do not increase and the ammonia response is exaggerated in individuals with MS subjected to anaerobic exercise [45].

The earliest versions of this test, subjected patients were submitted to ischemic exercise. However, because that test induced rhabdomyolysis and many patients quit before completing the test, non-ischemic or partially one tests were developed [46], [47]. Kazemi-Esfarjani, Skomorowska and Jensen [47] compared four different forearm test protocols, including the classic ischemic protocol with the dynamometer set intended maximal voluntary contraction force (MVC) and subsequent contractions over a one-minute period. According to those authors, a non-ischemic aerobic protocol at $100 \%$ of MVC is effective at detecting muscle glycolytic disorders because it is similar to the classic protocol and it is better tolerated by individuals with MS.

The scope of muscles MS implications is wide, as it is characterized by specific symptoms and muscle features that are mainly related to biochemical problems. 


\subsection{Metabolic implications}

Anaerobic lactic metabolism is impaired in individuals with MS due to significant reduction in oxidative phosphorylation caused by the low availability of glucose derived from glycogen breakdown, thus resulting in a reduction of the ATP resynthesis rate [48]. In healthy individuals, the myophosphorylase enzyme breaks glycogen down into glucose-1-phosphate. Then, other enzymes regulate the glycogen metabolism up to glycolysis, followed by its catabolism and energy release. In the case of individuals with MS, the reaction stops at the step at which glucose-1phosphate is released because the absence or dysfunction of the myophosphorylase enzyme impairs the breakdown of the 1-4- $\alpha$-glycosidic bonds in glycogen [19].

The deficiencies related to glycogen breakdown and energy production notwithstanding, the human body is able to improve its metabolism to produce energy from other sources. In the absence of glycolysis, the body soon increases the oxidation rate of free glucose available during exercise [49], which is accompanied by a reduction of the heart rate and sudden development of tolerance to exercise. This effect is known as "second wind" and occurs due to an increase in the muscle capacity for oxidative phosphorylation [50]. This glucose is crucial to compensate for the lack of glucose derived from the breakdown of muscle glycogen [51].

As noted above, the dramatic increase in the serum creatine kinase levels, which may reach as high as 4,000 U/L (normal values reach up to $500 \mathrm{U} / \mathrm{L}$ ), is one of the features characteristically exhibited by individuals with MS. This level of increase is considered to be a marker of possible muscle damage. Exacerbated increases of the serum creatine kinase levels may lead to episodes of rhabdomyolysis and consequent kidney injury.

Not all individuals with MS exhibit full suppression of myophosphorylase activity, and in such cases symptoms occur as a function of functional enzyme activity percentage. Vitamin B6, in the form of pyridoxal-5-phosphate (PLP), plays a relevant role in the functioning of myophosphorylase. PLP binds to lysine in the phosphorylase subunits, and this bond is relevant for appropriate phosphorylase activity. Individuals with MS who exhibit low myophosphorylase activity levels also exhibit dramatic reduction of the PLP levels [52]. A strong association with PLP reduction may be one of the factors involved in the failure of the residual myophosphorylase activity. The use of vitamin B6 supplements is effective at improving the residual myophosphorylase activity because it improves exercise tolerance, increases lactate level during exercise, and possibly also aids the regeneration of muscle fibers after episodes of rhabdomyolysis. Conversely, these manifestations of the disease might recur following the discontinuance of vitamin B6 [53], [54].

Although the lactate levels are normal at rest in individuals with MS, they cannot be raised during exercise, as would normally occur due to metabolism of glucose. In the human body, lactate has hormonal functions, such as the stimulation of testosterone secretion [55]. Consequently, hormones whose release is stimulated by increased lactate levels might be altered in MS patients [56].

Nutritional strategies have been sought for controlling the metabolic disorders present in MS patients. In a randomized, double-blind study conducted with 12 individuals with MS, Vissing, and Haller [49] found that the intake of $75 \mathrm{~g}$ of sucrose before exercise was able to increase the serum glucose level, which resulted in an increased exercise tolerance, and reduced heart rate in the treated group compared to the placebo group. Andersen et al. [57] showed that in spite of exaggerated lipid mobilization, the infusion of free fatty acids in individuals with MS subjected to exercise training did not have an effect, most likely because there is a metabolic bottleneck in the Krebs Cycle due to impaired glycolytic flux in MS patients.

\subsection{Relationship with physical activity}

Exercise has long been considered to be contraindicated in MS patients to avoid problems associated with myoglobinuria [30]. A lack of physical activity may aggravate the problems associated with MS, and the exertion tolerance of the affected individuals may reduce in parallel their oxidative capacity [23]. However, several studies have reported positive results of a potential treatment for MS. In the study by Haller et al. [22], eight individuals with MS were subjected to an anaerobic exercise program on a cycle ergometer for 14 weeks, and the work capacity, cardiac output, and oxygen uptake were monitored. The results showed increases in the participants' work capacity and oxygen uptake as well as an increase of the mitochondrial metabolism. These results suggest that individuals with MS should perform aerobic training to increase their mitochondrial oxidative capacity, thus reducing the odds of the occurrence of symptoms of the disease. In a study conducted with 46 individuals with MS, Maté-Muñoz et al. [58] found that the participants' peak oxygen uptake $\left(\mathrm{VO}_{2}\right)$ was much lower when compared to that of sedentary healthy individuals. In that study, the application of a progressive aerobic exercise program was associated with increases of the oxygen uptake and workload.

\section{The nervous system and McArdle Syndrome}

\subsection{Cognitive implications}


There are few studies on the association of cognitive impairment and MS. Although the evidence for such an association is weak, the concept should not be fully dismissed. One case report relative to another GSD showed that mutation of the enzyme phosphorylase b kinase might cause cognitive impairment in affected individuals [59]. There is a single case report in the literature indicating an association between cognitive impairment and MS. Although Mancuso et al. [60] reported an association between cognitive impairment and MS, that study was based on previous evidence related to other case studies and other isoenzymes. Thus, the reported finding may have been observed due merely to chance.

\subsection{Neural (neuromuscular) implications}

The fibers composing the human skeletal muscle are innervated by large myelinated nerve fibers originating in spinal cord motor neurons. For muscle contraction to occur normally, an action potential must travel along the membranes of the nerve fibers.

According to Lorenzoni [32], electromyography has been used for the clinical assessment of individuals with suspected metabolic myopathy ever since the first description of MS in 1951. Indeed, this method is practical, and simple, and plays a relevant role in the diagnosis and follow-up of conditions that lead to fatigue of the muscle tissue [61].

An analysis of the results of studies on motor nerve conduction following short-term maximal muscular effort or repeated stimulation may reveal findings typical of MS. In MS, the electromyographic findings vary as a function of the moment at which the test is performed and the severity of disease, so results may be normal in patients with recent onset disease.

Neurophysiological studies showed that MS also involves the impairment of muscle fiber membrane excitability during contraction. Haller et al. [62] detected low sodium-potassium pump ( $\mathrm{Na}^{+} / \mathrm{K}^{+} \mathrm{ATPase}$ ) levels in the extracellular membrane, with consequent impairment of the ion transport across the membrane and increase of the extracellular potassium concentration. In turn, exaggerated extracellular potassium levels decrease the membrane excitability during muscle contraction, which accounts for the reduction found in the muscle action potential following physical exertion or repeated stimulation. The mechanism of impaired $\mathrm{Na}^{+} / \mathrm{K}^{+}$ATPase functioning in MS is not fully elucidated, but it may be related to the inadequate supply of ATP produced by glycolysis to the muscle fiber $\mathrm{Na}^{+} / \mathrm{K}^{+} \mathrm{ATPase}$ pump [63]

In a study with MS patients, Lorenzoni et al. [32] found changes in the motor nerve conduction following short-term voluntary muscle exertion or high-frequency repetitive stimulation. In most patients, the amplitude of the muscle action potential exhibited a significant reduction after a 30 - or 90 -second effort, returning to its normal level after a period of rest.

Other studies that applied electromyography found that patients with MS require more motor unit recruitment for a given power output compared to healthy individuals, which may be one of the causes of their intolerance to exercise [64].

\section{Conclusion}

A short review of MS showed that it is associated with a broad scope of symptoms that involve the muscles and cause metabolic and, possibly, cognitive impairment, metabolic dysfunction due to myophosphorylase deficiency, and impairment of the membrane potential and $\mathrm{Na}^{+} / \mathrm{K}^{+}$ATPase pumps. Although there is no cure for MS, treatment by means of low-to-moderate intensity exercise induces benefits in the affected individuals, such as an increase of the mitochondrial metabolism. Accordingly, the discontinuance of training may be followed by the reappearance of symptoms of the disease.

\section{References}

[1] S.Tsujino, I.Nonaka, S.DiMauro,Glycogen storage myopathies,Neurologic clinics, 18 (2000) 125-150.http://dx.doi.org/10.1016/S0733$\underline{8619(05) 70181-X}$

[2] I.J.Wolfsdorf,I.A. Holm, D.A.Weinstein,Glycogen storage diseases: phenotypic, genetic, and biochemical characteristics, and therapy,Endocrinology and metabolism clinics of North America, 28 (1999) 801-823.http://dx.doi.org/10.1016/S0889-8529(05)70103-1.

[3] E. Gazzerro, A.L.Andreu, C.Bruno,Neuromuscular disorders of glycogen metabolism,Current neurology and neuroscience reports, 13 (2013) 1-12.http://dx.doi.org/10.1007/s11910-012-0333-0.

[4] S.DiMauro, C.Lamperti,Muscleglycogenoses,Muscle\& nerve, 24 (2001) 984-999.http://dx.doi.org/10.1002/mus.1103.

[5] J.Y.Chou, B.C.Mansfield,Mutations in the glucose-6-phosphatase- $\alpha$ (G6PC) gene that cause type Ia glycogen storage disease,Human mutation, 29 (2008) 921-930.http://dx.doi.org/10.1002/humu.20772.

[6] P.S.Kishnani, R.D.Steiner, D.Bali, et al.,Pompe disease diagnosis and management guideline, Genetics in Medicine, 8 (2006) 267288.http://dx.doi.org/10.1097/01.gim.0000218152.87434.f3.

[7] S. Lucchiari, D.Santoro, S.Pagliarani, G.P.Comi,Clinical, biochemical and genetic features of glycogendebranching enzyme deficiencyActamyologica, 26 (2007) 72.

[8] S.Li, C.M.Chen, L.J.Goldstein, et al., Glycogen storage disease type IV: novel mutations and molecular characterization of a heterogeneous disorder,Journal of inherited metabolic disease, 33 (2010) 83-90.http://dx.doi.org/10.1007/s10545-009-9026-5.

[9] Y.SShin,Glycogen storage disease: clinical, biochemical, and molecular heterogeneity,Seminars in pediatric neurology, 13 (2006) 115120.http://dx.doi.org/10.1016/j.spen.2006.06.007. 
[10] N.J.Beauchamp, J.Taybert, M.P.Champion, et al.High frequency of missense mutations in glycogen storage disease type VI,Journal of inherited metabolic disease, 30 (2007) 722-734.http://dx.doi.org/10.1007/s10545-007-0499-9.

[11] O.Musumeci, C.Bruno, T.Mongini, et al.Clinical features and new molecular findings in muscle phosphofructokinase deficiency (GSD type VII), Neuromuscular Disorders, 22 (2012) 325-330.http://dx.doi.org/10.1016/j.nmd.2011.10.022.

[12] C.Lau, J.Hui, F.N.Hong, et al.Novel mutations in PHKA2 gene in glycogen storage disease type IX patients from Hong Kong, China,Molecular genetics and metabolism, 102 (2011) 222-225.http://dx.doi.org/10.1016/j.ymgme.2010.11.004.

[13] R.Santer, B.Steinmann, J.Schaub,Fanconi-Bickel syndrome-a congenital defect of facilitative glucose transport,Current molecular medicine, 2 (2002) 213-227.http://dx.doi.org/10.2174/1566524024605743.

[14] A.Toscano, O. Musumeci,Tarui disease and distal glycogenoses: clinical and genetic update,ActaMyologica, 26 (2007) 105.

[15] G.P.Comi, F.Fortunato, S.Lucchiari, et al. $\beta$-enolase deficiency, a new metabolic myopathy of distal glycolysis, Annals of neurology, 50, (2001) 202-207.http://dx.doi.org/10.1002/ana.1095.

[16] T.Stojkovic, J.Vissing, F.Petit, et al.Muscleglycogenosis due to phosphoglucomutase 1 deficiency,New England Journal of Medicine, 361(2009) 425-427.http://dx.doi.org/10.1056/NEJMc0901158.

[17] M.Orho, N.O.Bosshard, N.R.Buist, et al.Mutations in the liver glycogen synthase gene in children with hypoglycemia due to glycogen storage disease type 0,Journal of Clinical Investigation1998, 102(1998) 507.

[18] C.M.Pearson, D.G.Rimer, W.F.Mommaerts,A metabolic myopathy due to absence of muscle phosphorylase,The American journal of medicine, 30(1961) 502-517.http://dx.doi.org/10.1016/0002-9343(61)90075-4.

[19] A.Lucia,McArdle disease: what do neurologists need to know?,Nature Clinical Practice Neurology, 4 (2008) 568577.http://dx.doi.org/10.1038/ncpneuro0913.

[20] R.Quinlivan,McArdle disease: a clinical review.Journal of Neurology, Neurosurgery \& Psychiatry, 81 (2010) 11821188.http://dx.doi.org/10.1136/jnnp.2009.195040.

[21] R.Quinlivan, A.Martinuzzi, B.Schoser,Pharmacological and nutritional treatment for McArdle disease (Glycogen Storage Disease type V),Cochrane Database SystRevB (2010).http://dx.doi.org/10.1002/14651858.cd003458.pub4.

[22] R.G.Haller, P.Wyrick, T.Taivassalo, J, et al.Aerobic conditioning: an effective therapy in McArdle's disease,Annals of neurology, 59 (2006) 922-928.http://dx.doi.org/10.1002/ana.20881.

[23] B.Saltin, P.D.Gollnick, Skeletal muscle adaptability: significance for metabolism and performance.Comprehensive Physiology, (2011)555631.http://dx.doi.org/10.1002/cphy.cp100119.

[24] A.Lucia, J.R.Ruiz, A. Santalla,et al.Genotypic and phenotypic features of McArdle disease: insights from the Spanish national registry,Journal of Neurology, Neurosurgery \& Psychiatry, 83 (2012) 322-328.http://dx.doi.org/10.1136/jnnp-2011-301593.

[25] B.McArdle,Myopathy due to a defect in muscle glycogen breakdown, Clinical Science, 10 (1951), 13-35.

[26] M.A.Martín,Molecular heterogeneity of myophosphorylase deficiency (McArdle's disease): a genotype-phenotype correlation study,Annals of neurology, 50 (2001) 574-581.http://dx.doi.org/10.1002/ana.1225.

[27] R.Aquaron, J.L.Bergé-Lefranc, J.F.Pelissier, et al,Molecular characterization of myophosphorylase deficiency (McArdle disease) in 34 patients from Southern France: identification of 10 new mutations. Absence of genotype-phenotype correlation,Neuromuscular Disorders, 17(2007) 235-241.http://dx.doi.org/10.1016/j.nmd.2006.12.014.

[28] O.Rommel, R.A.Klay, G.Dekomien, J.T.Epplen, M.Vogerd, M.Hasenbring, Muscle pain in myophosphorylase deficiency (McArdle's disease): the role of gender, genotype, and pain-related coping,Pain, 124 (2006) 295-304.http://dx.doi.org/10.1016/j.pain.2006.04.017.

[29] J.Zange, T.Grehl,C.Disselhorst-Klug,etal.Breakdown of adenine nucleotide pool in fatiguing skeletal muscle in McArdle's disease: A noninvasive 31P-MRS and EMG study.Muscle\& nerve, 27 (2003) 728-736.http://dx.doi.org/10.1002/mus.10377.

[30] F.Miteff, H.C.Potter, J.Allen, H.Teoh, R.Roxburgh, D.OHutchinson,Clinical and laboratory features of patients with myophosphorylase deficiency (McArdle disease).Journal of Clinical Neuroscience, 18(2011) 1055-1058.http://dx.doi.org/10.1016/j.jocn.2010.12.033.

[31] A.Delibaş, K.Bek, F.S.Ezgü, G.Demircin, A.Oksal, A.Oner,Acute renal failure due to rhabdomyolysis in a child with McArdle disease,European journal of pediatrics, 167 (2008). 939-940.http://dx.doi.org/10.1007/s00431-007-0591-z.

[32] P.J.Lorenzoni, M.C.Lange, C.S.Kay, R.H.Scola, L.C.Werneck,Motor nerve conduction study in McArdle disease: case report, Arquivos de neuro-psiquiatria, 63 (2005) 874-877http://dx.doi.org/10.1590/S0004-282X2005000500031.

[33] R.Costa, A.Costa, R.Taipa, R.Vizcaíno, T.Morgado,Mcardle disease presenting with rhabdomyolisis and acute kidney injury,Actamedicaportuguesa, 26 (2012) 463-466.

[34] S.Moustafa, D.J.Patton, M.S.Connelly,Unforeseen Cardiac Involvement in McArdle's Disease,Heart, Lung and Circulation, 22(2013) 769771.http://dx.doi.org/10.1016/j.hlc.2012.12.004.

[35] D.P.Nicholls, N.P.Campbell, H.P.Stevenson, V.H.Patterson, Angina in McArdle's disease,Heart, 76(1996) 372373.http://dx.doi.org/10.1136/hrt.76.4.372.

[36] J.Vissing, R.G.Haller,A diagnostic cycle test for McArdle's disease,Annals of neurology, 54 (2003)539542.http://dx.doi.org/10.1002/ana.10725

[37] N.Voduc, K.A.Webb, C.D'Arsigny, I.McBride, D.E.O'Donnell,McArdle's disease presenting as unexplained dyspnea in a young woman,Canadian respiratory journal, 11(2004) 163-167.

[38] K.J. Felice, A.B.Schneebaum, H.R.Jones,McArdle's disease with late-onset symptoms: case report and review of the literature,Journal of Neurology, Neurosurgery \& Psychiatry, 55 (1992) 407-408.http://dx.doi.org/10.1136/jnnp.55.5.407.

[39] G.I.Wolfe, N.S.Baker, R.G.Haller, D.K.Burns, R.J.Barohn,McArdle's disease presenting with asymmetric, late-onset arm weakness,Muscle\& nerve, 23 (2000) 641-645.http://dx.doi.org/10.1002/(SICI)1097-4598(200004)23:4<641::AID-MUS25>3.0.CO;2-M.

[40] A.A. Nadaj-Pakleza, G.M.Vincitorio, P.Laforêt, et al. Permanent muscle weakness in McArdle disease,Muscle\& nerve, 40(2009) 350357.http://dx.doi.org/10.1002/mus.21351.

[41] J.C.Rubio, M.A.Martín, J.Bautista, et al.Myophosphorylase deficiency associated with a defect in complex I of the mitochondrial respiratory chain,Journal of the neurological sciences, 161 (1998) 110-113.http://dx.doi.org/10.1016/S0022-510X(98)00263-9.

[42] R.W.Byard, B.Laceu, D.N.Preston, Peripheral nerve and vasculature involvement in myophosphorylase deficiency (McArdle's disease), Pathology, 23 (1991) 62-65.http://dx.doi.org/10.3109/00313029109061442.

[43] M. Scarpelli, G.Vattemi, M.Filosto, et al. McArdle disease and sporadic inclusion body myositis, Neuropathology and applied neurobiology, 35(2009) 442-445.http://dx.doi.org/10.1111/j.1365-2990.2009.01019.x.

[44] S.Tsujino, S.Shanske, J.E.Carroll,Double trouble: combined myophosphorylase and AMP deaminase deficiency in a child homozygous for nonsense mutations at both loci,Neuromuscular Disorders, 5 (1995) 263-266.http://dx.doi.org/10.1016/0960-8966(94)00062-E.

[45] B.McArdle, D.Verel,Responses to ischaemic work in the human forearm,Clinical science (London), 15 (1956) $305-318$.

[46] H.M. Meinck, H.H.Goebel, K.W.Rumpf, H.Kaiser, P.Neumann, The forearm ischaemic work test--hazardous to McArdle patients?,Journal of Neurology, Neurosurgery \& Psychiatry, 45 (1982) 1144-1146.http://dx.doi.org/10.1136/jnnp.45.12.1144.

[47] P.Kazemi-Esfarjani, R.Skomorowska, T.D. Jensen, R.G.Haller, J.Vissing, A nonischemic forearm exercise test for McArdle disease, Annals of neurology, 52(2002) 153-159.http://dx.doi.org/10.1002/ana.10263.

[48] S.F.Lewis, R.G.Haller,The pathophysiology of McArdle's disease: clues to regulation in exercise and fatigue,Journal of applied physiology, 61(1986) 391-401 
[49] J. Vissing, R.G.Haller, The effect of oral sucrose on exercise tolerance in patients with McArdle's disease,New England Journal of Medicine, 349(2003) 2503-2509.http://dx.doi.org/10.1056/NEJMoa031836.

[50] B.B.Pernow, R.J.Havel, D.B.Jennings,The second wind phenomenon in McArdle's syndrome.ActaMedicaScandinavica, 181(1967) 294307.http://dx.doi.org/10.1111/j.0954-6820.1967.tb12635.x.

[51] S.T.Andersen, J.Vissing, Carbohydrate-and protein-rich diets in McArdle disease: effects on exercise capacity, Journal of Neurology, Neurosurgery \& Psychiatry, 79(2008) 1359-1363.http://dx.doi.org/10.1136/adc.2008.146548.

[52] R.Haller, W.B.Dempsey, H.Feit, J.D.Cook, J.PKnochel, Low muscle levels of pyridoxine in McArdle's syndrome, The American journal of medicine, 74(1983) 217-220.http://dx.doi.org/10.1016/0002-9343(83)90614-9.

[53] J.Phoenix, P.Hopkins, C.Bartram, R.J.Beynon, R.C.Quinlivan, R.H.Edwards,Effect of vitamin B6 supplementation in McArdle's disease: a strategic case study,Neuromuscular Disorders, 8(1998) 210-212.http://dx.doi.org/10.1016/S0960-8966(98)00004-2.

[54] S.Sato, T.Ohi, I.Nishino, H.Sugie, Confirmation of the efficacy of vitamin B6 supplementation for McArdle disease by follow-up muscle biopsy,Muscle\& nerve, 45(2012) 436-440.http://dx.doi.org/10.1002/mus.22290.

[55] S.Lu, C.P.Lau, Y.Tung,Lactate and the effects of exercise on testosterone secretion: evidence for the involvement of a cAMP-mediated mechanism,Medicine and science in sports and exercise, 29(1997) 1048-1054.http://dx.doi.org/10.1097/00005768-199708000-00010.

[56] R.J.Godfrey, G.P.Whyte, J.Buckley, R.Quinlivan,The role of lactate in the exercise-induced human growth hormone response: evidence from McArdle disease, British journal of sports medicine, 43(2009) 521-525.http://dx.doi.org/10.1136/bjsm.2007.041970.

[57] S.T.Andersen, T.D.Jeppesen, T.Taivassalo, Effect of changes in fat availability on exercise capacity in McArdle disease, Archives of neurology, 66(2009) 762-766.http://dx.doi.org/10.1001/archneurol.2009.93.

[58] J.L.Maté-Munoz, M.Moran, M.Pérez, et al,Favorable responses to acute and chronic exercise in McArdle patients, Clinical Journal of Sport Medicine, 17(2007) 297-303.http://dx.doi.org/10.1097/JSM.0b013e3180f6168c.

[59] A, Echaniz-Laguna, H.O. Akman, M. Mohr, et al.Musclephosphorylase b kinase deficiency revisited,Neuromuscular Disorders, 20(2010) 125127.http://dx.doi.org/10.1016/j.nmd.2009.11.004.

[60] M.Mancuso, D.Orsucci, D.Volterrani, S.Siciliano, Cognitive impairment and McArdle disease: Is there a link?, Neuromuscular Disorders, 21(2011) 356-358.http://dx.doi.org/10.1016/j.nmd.2011.02.013.

[61] D.R.Rogers, D.T.MacIsaac,A comparison of EMG-based muscle fatigue assessments during dynamic contractions,Journal of Electromyography and Kinesiology, 23(2013) 1004-1011.

[62] R.DHaller, T.Clausen, J.Vissing,Reduced levels of skeletal muscle Na+ K+-ATPase in McArdle disease,Neurology50(1998) 37-40.

[63] T.Clausen, Na+-K+ pump regulation and skeletal muscle contractility.Physiological reviews, 83(2003) 12691324.http://dx.doi.org/10.1152/physrev.00011.2003.

[64] D.E.Rae, T.D.Noakes, A.F. San-Juan, et al,Excessive skeletal muscle recruitment during strenuous exercise in McArdle patients,European journal of applied physiology, 110(2010) 1047-1055.http://dx.doi.org/10.1007/s00421-010-1585-5. 